\title{
Caroticocavernous Fistulae: Clinical Presentation, Imaging, and Endovascular Treatment
}

\author{
Pushpinder S. Khera ${ }^{1}$ Pawan K. Garg ${ }^{1}$ Sarbesh Tiwari ${ }^{1}$ Binit Sureka ${ }^{1}$ Taruna Yadav ${ }^{1}$ \\ Sukalyan Purkayastha ${ }^{2}$ Suryanarayanan Bhaskar ${ }^{3}$ Pradeep Bhatia ${ }^{4}$ Arvind Morya ${ }^{5}$
}

1Department of Diagnostic and Interventional Radiology, All India
Institute of Medical Sciences, Jodhpur, India
${ }^{2}$ Department of Interventional Radiology, Institute of
Neurosciences, Kolkata, India
${ }^{3}$ Department of Neurosurgery, All India Institute of Medical
Sciences, Jodhpur, India
${ }^{4}$ Department of Anaesthesiology and Critical Care, All India
Institute of Medical Sciences, Jodhpur, India
${ }^{5}$ Department of Ophthalmology, All India Institute of Medical
Sciences, Jodhpur, India

J Clin Interv Radiol ISVIR 2019;3:171-179

\begin{abstract}
Address for correspondence Pawan Kumar Garg, MD DNB, Room No. 28, Department of Diagnostic and Interventional Radiology, All India Institute of Medical Sciences, Basni, Jodhpur, Rajasthan, India 342005 (e-mail: drgargpawan@gmail.com).
\end{abstract}

\author{
Abstract \\ Keywords \\ - caroticocavernous \\ fistula \\ - proptosis \\ - embolization
}

Caroticocavernous fistulas (CCFs) occur due to an abnormal communication between the high-pressure carotid artery system and the relatively lower pressure cavernous sinus system. They present with dramatic clinical presentations comprising among other things a swollen red eye with associated loss of vision to a varying degree. Blunt trauma sustained to the head, especially by two-wheeler riders, is the most common cause of the direct CCF and hence a practicing interventional radiologist in a developing country is very likely to encounter this entity in clinical practice. The authors intend to present a pictorial essay of the clinical presentations, imaging findings, endovascular management, and clinical follow-up for CCFs.

\section{Introduction}

Caroticocavernous sinus fistulae (CCFs) result from abnormal communication between the carotid system arteries and the cavernous sinus. ${ }^{1,2}$ The resultant increase in cavernous sinus pressure is the main reason for the clinical features and complications of this entity. Advances in endovascular techniques have resulted in this approach to have become the mainstay of treatment for CCFs.

\section{Classification and Etiology of CCFs}

Caroticocavernous sinus fistulae can be categorized according to etiology (spontaneous or posttraumatic), hemodynamic effects (high or low flow), and angiographic findings (direct or indirect). It is the latter which forms the basis of classification proposed by Barrow et $\mathrm{al}^{3}$ and is the most helpful to plan a therapeutic treatment strategy. ${ }^{1}$ According to this classification system the CCFs can be categorized into four distinct types (-Table $\mathbf{1}$ ).

\section{Etiological Classification}

a. Traumatic CCFs mostly demonstrate a single direct communication between internal carotid artery (ICA) (most commonly the proximal horizontal cavernous segment) and cavernous sinus and are hence type A. ${ }^{1}$ Bilateral traumatic CCFs are extremely rare and mostly associated with extensive head injury, and are commonly fatal. ${ }^{5}$

b. Spontaneous CCFs may be of any of the four types since a type A shunt can develop following a spontaneous rupture of cavernous ICA aneurysm. More commonly, spontaneous CCF is an indirect CCF and has low flow rates. The main arterial supply to indirect fistulas originates from internal maxillary, ascending pharyngeal, accessory meningeal, and middle meningeal branches of external carotid artery (ECA) and cavernous branches of ICA. They occur more commonly in postmenopausal women and have an association with diabetes mellitus, hypertension, pregnancy, and atherosclerosis. ${ }^{6-8}$ Trauma is only very rarely associated with indirect CCF. ${ }^{9}$

\section{received}

January 22, 2019

accepted

April 29, 2019

published online

December 4, 2019
DOI https://doi.org/

10.1055/s-0039-3400432

ISSN 2457-0214.
(C)2019 by Indian Society of Vascular and Interventional Radiology
License terms

(®) $\Theta \circledast$ 
Table 1 Angiographic classification of caroticocavernous fistulas

\begin{tabular}{|l|l|}
\hline Type A & $\begin{array}{l}\text { Direct communication between Internal carotid ar- } \\
\text { tery (ICA) and cavernous sinus leading to a high-flow } \\
\text { fistula ( } \text { - Fig. 1) }\end{array}$ \\
\hline Type B & $\begin{array}{l}\text { Indirect dural arteriovenous fistulas centered on } \\
\text { cavernous sinus being fed by branches of ICA }\end{array}$ \\
\hline Type C & $\begin{array}{l}\text { Indirect dural arteriovenous fistulas centered on cav- } \\
\text { ernous sinus being fed by branches of external carotid } \\
\text { artery (ECA) }\end{array}$ \\
\hline Type D & $\begin{array}{l}\text { Indirect dural arteriovenous fistulas centered on } \\
\text { cavernous sinus being fed by branches of both ICA } \\
\text { and ECA ( - Fig. 2) }\end{array}$ \\
\hline
\end{tabular}

${ }^{a}$ Tomsick $^{4}$ further subdivided type D into D1 (unilateral) and D2 (bilateral).

\section{Clinical Features}

A CCF leads to transmission of high-pressure arterial blood into cavernous sinus and its various tributaries, that is, superior and inferior ophthalmic veins anteriorly, the superior petrosal and inferior petrosal sinuses and basilar plexus posteriorly, the pterygoid plexus inferiorly, the sphenoparietal sinus laterally, and cavernous sinus contralaterally. ${ }^{10}$

It is this redirection of high-pressure flow into the venous system that causes the clinical symptomatology of CCF (-Fig. 1).

The orbital diversion of flow leads to orbital venous congestion and transudation of interstitial fluid into orbit with resultant proptosis and chemosis. Presence of an orbital bruit on auscultation completes the Dandy's triad ${ }^{1}$ : exophthalmos, bruit, and conjunctival chemosis which, however, is not found in most patients of CCF. Most patients present with

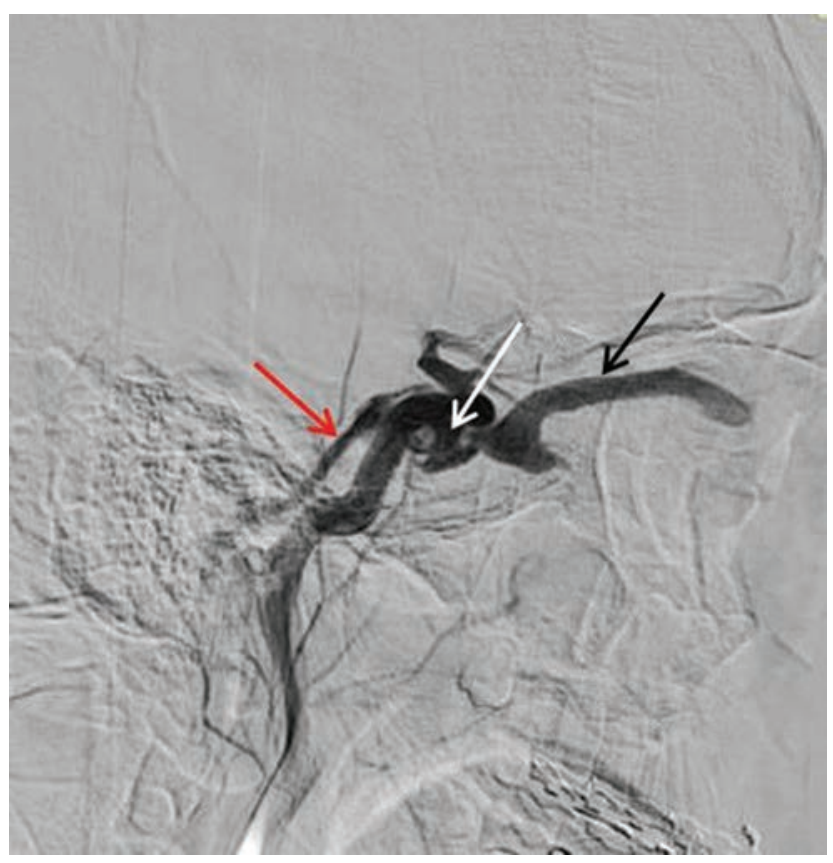

Fig. 1 Lateral ICA angiogram showing a direct CCF with a rent (white arrow) between the distal horizontal ICA and cavernous sinus. Reflux is seen into the SOV (black arrow) and inferior petrosal sinus (red arrow). proptosis (90\%); chemosis (90\%); diplopia (50\%); bruit (25\%); orbital pain (25\%); III, IV, V, and VI nerve palsies; raised intraorbital pressure (IOP); and some form of visual loss (50\%) due to impaired drainage of aqueous humor. ${ }^{1,11}$

Raised venous pressure and IOP can compromise retinal perfusion, leading to severely diminished visual acuity. ${ }^{1}$

Hence any visual loss warrants immediate treatment of a CCF. Whereas minor deficit in visual acuity resolve completely in most cases post treatment, severe loss with loss of perception of light rarely improves even with successful treatment. $^{12}$

Incidence of intracranial hemorrhage is 5\% and it occurs due to cortical venous hypertension ( - Fig. 2). Massive epistaxis due to formation of pseudoaneurysmal cavernous sinus varix can manifest in 1 to $2 \%$ of the cases. ${ }^{13}$ Similarly rupture of dilated veins draining the ear canal can lead to massive otorrhagia. ${ }^{13,14}$

It must be noted that indirect CCFs progress more insidiously and most cases present with slowly progressive glaucoma and relatively moderate proptosis or conjunctival injection ${ }^{1,15,16}$ (-Fig. 3).

Exacerbations and remissions are hallmark of CCF (both direct and indirect), likely due to cavernous sinus thrombosis and rerouting of venous flow. ${ }^{1}$ Incidence of spontaneous resolution of indirect CCFs ranges from 10 to $60 \%$ in literature ${ }^{17}$ whereas symptomatic high flow direct CCFs rarely regress on their own. ${ }^{18}$

It is important to bear in mind that any change or improvement in symptoms of a CCF should alert the treating physician to an alteration in venous drainage and a possible switch to a higher risk central or spinal pial draining pattern
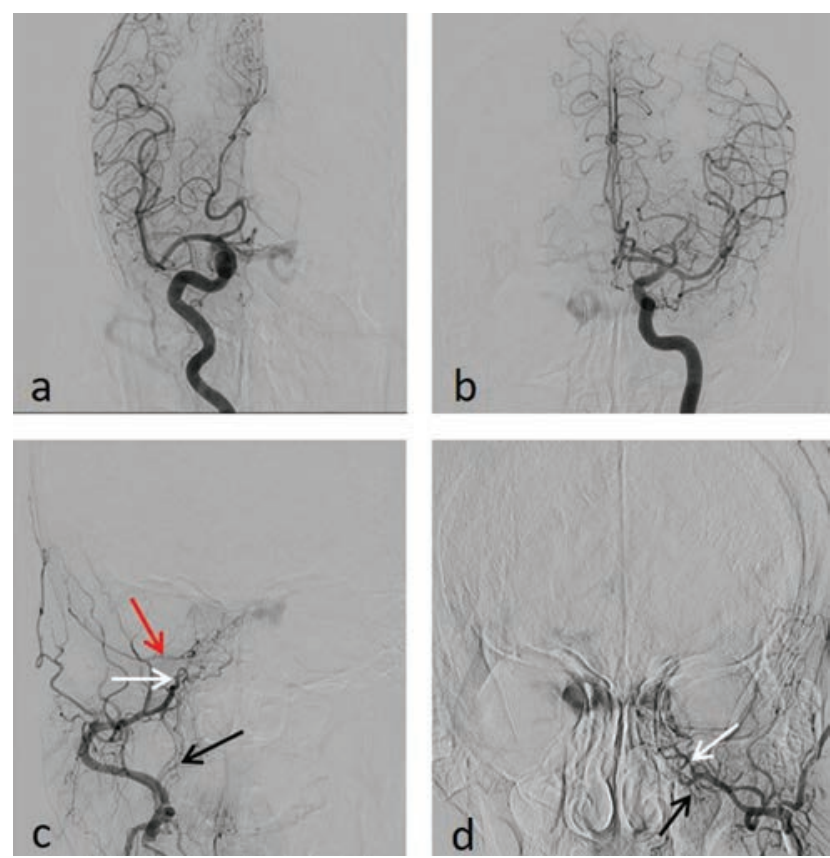

Fig. 2 Type D2 CCF: Selective frontal angiograms of bilateral ICAs (a,b) and ECAs (c,d) show opacification of left cavernous sinus with feeders from dural branches of bilateral cavernous ICAs and middle meningeal (red arrows), anterior meningeal (black arrows), and ascending pharyngeal branches (black arrows) of bilateral ECAs. The right cavernous sinus is opacified through the intercavernous communication. 
predisposing to life-threatening venous bleed and myelopathy, respectively ( - Table 2 ). ${ }^{1}$

\section{Imaging Evaluation}

Doppler evaluation of affected eye shows a prominent superior ophthalmic vein with arterialized flow (-Fig. 4) consistent with an arteriovenous fistula.

Computed tomography (CT) and CT angiography (CTA) show proptosis of affected eye with swelling of extraocular muscles (EOMs), dilatation, and tortuosity of superior opthalmic vein (SOV) and ipsilateral cavernous sinus (-Fig. 5a). In addition, CTA can show location of the rent in many cases of direct CCFs ( $\mathbf{- F i g}$. $\mathbf{5 b}$ ) as well as size of cavernous sinus pouch, which helps to decide the selection of coil size for treatment. The volume rendered (VR) images also help in locating the SOV in cases where direct exposure of this vein is required for accessing the cavernous sinus in indirect CCFs ( - Fig. 5c). In addition, CT is excellent to evaluate for any bony
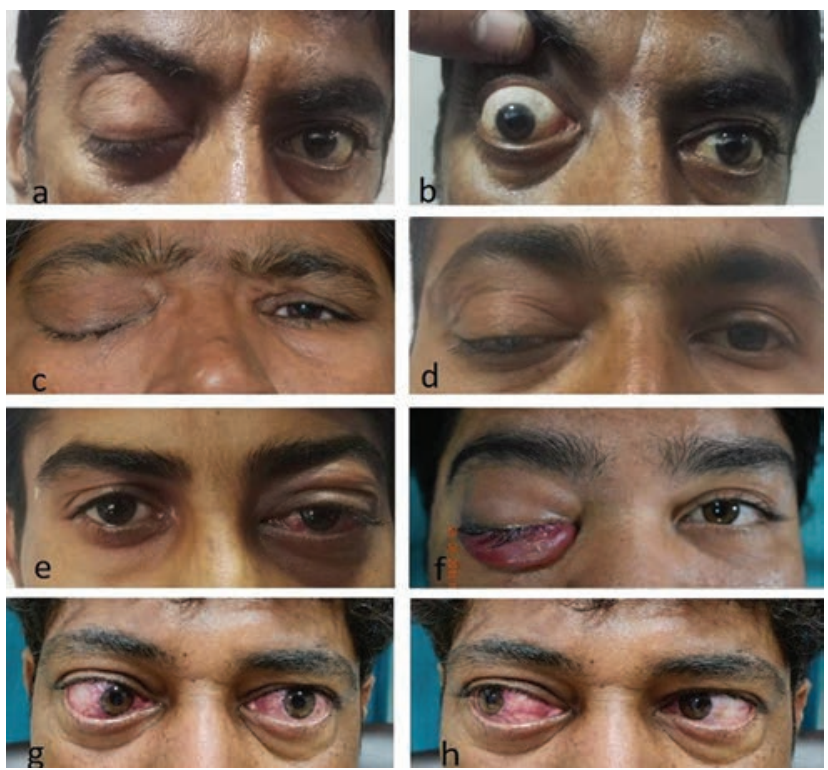

Fig. 3 Myriad clinical presentations of direct CCF: (a,b) A 45-year-old man with complete ptosis and severe proptosis right eye with no chemosis. (c,d) Two different patients having complete and partial ptosis. Patients having mild (e) and severe (f) chemosis and proptosis. ( $(\mathbf{g})$ and $(\mathbf{h})$ show a patient having bilateral proptosis and chemosis with left abducens palsy due to right direct CCF. injuries of skull base especially ones which may compress the carotid lumen. ${ }^{1}$

Magnetic resonance imaging (MRI) shows the orbital edema and abnormal flow voids thereby confirming high flow within the orbital veins. MRI may also show prominent cerebral veins.

Digital subtraction angiography (DSA) of cerebral arteries remains the mainstay and gold standard for diagnosis and treatment planning of CCFs.

All cases of CCF should undergo an angiogram with selective cannulation of bilateral ECAs and ICAs.

The angiogram should be able to provide the following information: ${ }^{1,2,5,15,16}$

Table 2 Dangerous signs which are indications for early/ emergency treatment ${ }^{1,14,18}$

\begin{tabular}{|l|c|}
\hline Clinical signs and symptoms & Angiographic signs \\
\hline - Severe headache (indicates & - CVR ( - Fig. 2) \\
central venous reflux and a high & - Varix of cavernous \\
risk of bleeding) & sinus (-Fig. 8) \\
- Raised intracranial pressure & - Pseudoaneurysm of \\
- Rapid progression of proptosis & carotid artery \\
- Diminished visual acuity & \\
- Hemorrhage (intracranial, sub- & \\
arachnoid, otorrhagia, epistaxis) & \\
- TIA (signifies significant steal) & \\
\hline
\end{tabular}

Abbreviations: CVR, central venous reflux; TIA, transient ischemic attack.

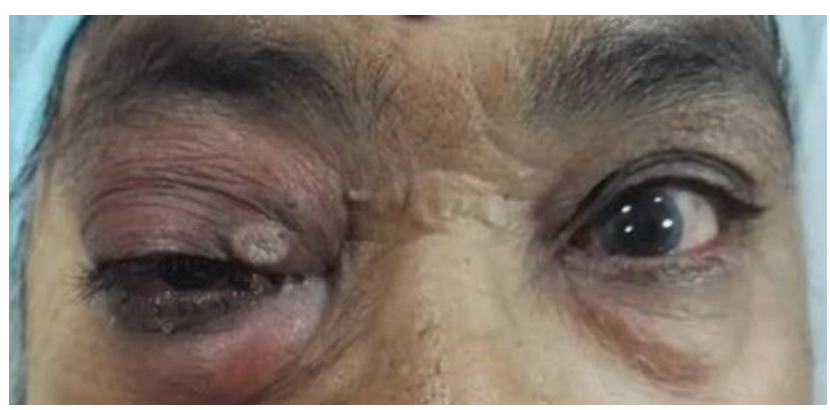

Fig. 5 A 63-year-old lady presented with 2 months history of gradually progressive chemosis and ptosis right eye. Her DSA revealed a type D2 CCF (see - Fig. 2 ).

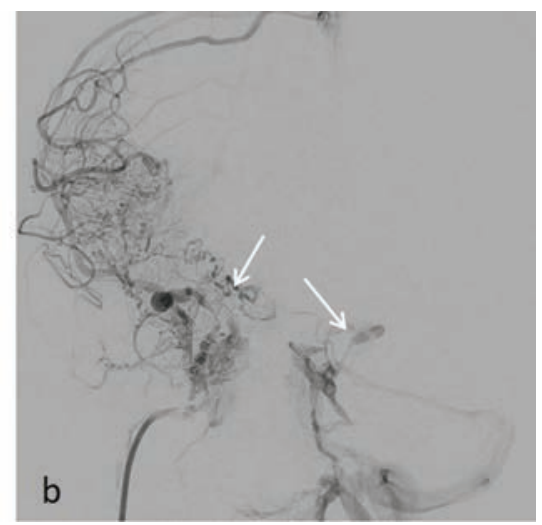

Fig. 4 Frontal right ICA angiogram of a patient with right direct CCF shows significant reflux into the right sylvian vein (black arrow), bilateral pial veins (white arrow), and right cortical veins (red arrow). 


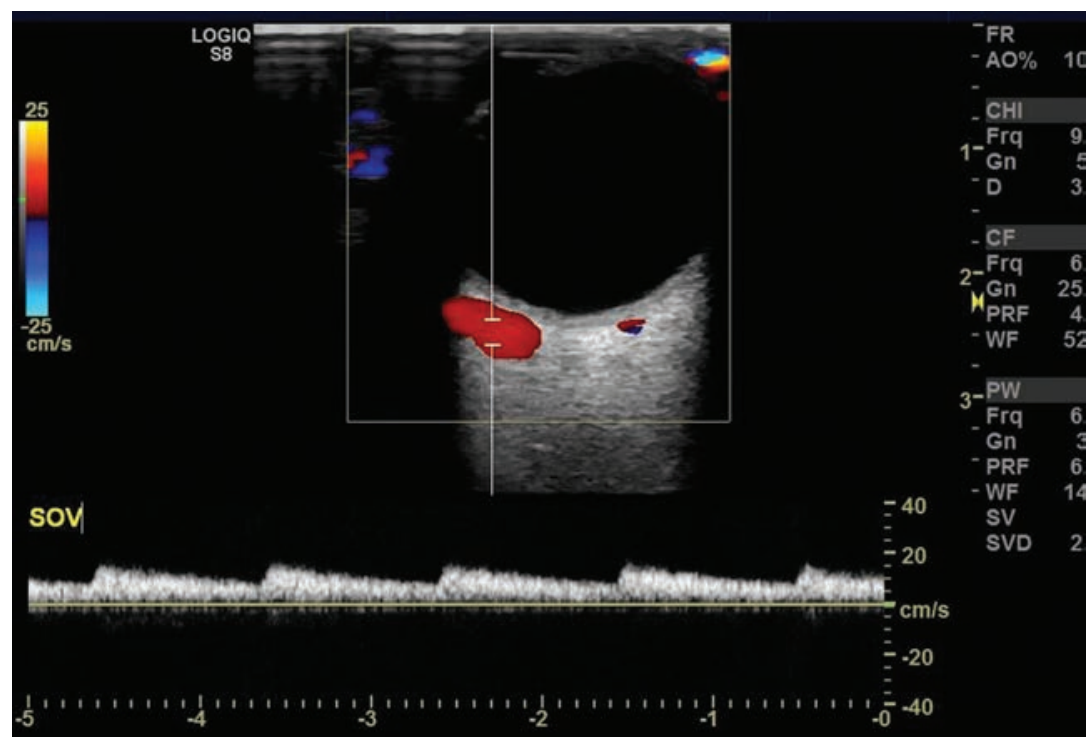

Fig. 6 Doppler of the orbit in a case of direct CCF shows reversed arterialized flow in the superior ophthalmic vein (SOV).
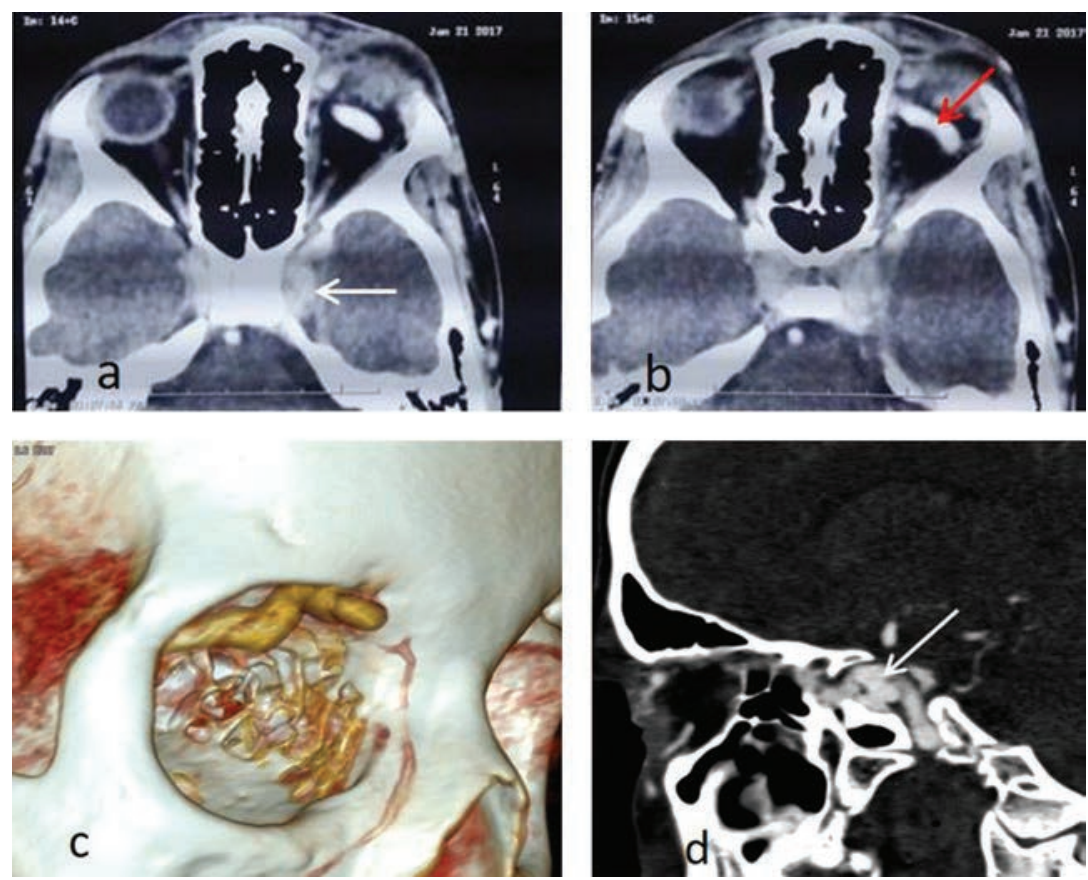

Fig. 7 (a, b) Contrast-enhanced CT in a case of left-sided direct CCF shows prominent left cavernous sinus (white arrow) and dilated left SOV (red arrow). (c) Volume-rendered image of CT angiography for an indirect CCF shows the dilated SOV in relation to the superior margin of orbit. (d) Sagittal reconstruction of CT angiography maximal intensity projection shows the rent in cavernous ICA (arrow).

- Size, location, and number of fistula(s) (since there may be multiple rents).

- Differentiating direct versus indirect fistula ( - Figs. 6 and $\mathbf{7}$ ).

- Assessment of cervical ICA for any associated injury such as dissection or pseudoaneurysm.

- Any associated cavernous carotid aneurysm/venous varix (-Fig. 8).

- Quality of antegrade flow (presence/absence of steal phenomenon).

- Collateral flow through circle of Willis (important in cases when parent artery occlusion is being planned (-Fig. 9).
- Degree of central venous reflux(CVR):- Figure 2.

- Balloon test occlusion should be performed in case ICA occlusion is being contemplated as a means of treatment.

Successful demonstration of fistula in a direct CCF depends on several factors such as number, location, and size of rent in the ICA. The following methods help to improve the diagnostic accuracy of the study ( - Fig. 10):

1. Using a high frame rate ( $>5 \mathrm{fps}$ ) during acquisition. ${ }^{1,18}$

2. Using pure contrast at high injection rate $(7-8 \mathrm{~mL} / \mathrm{sec}){ }^{1,18}$

3. Using Mehringer and Heishiema or Heuber maneuvers. ${ }^{1,18,19}$ 


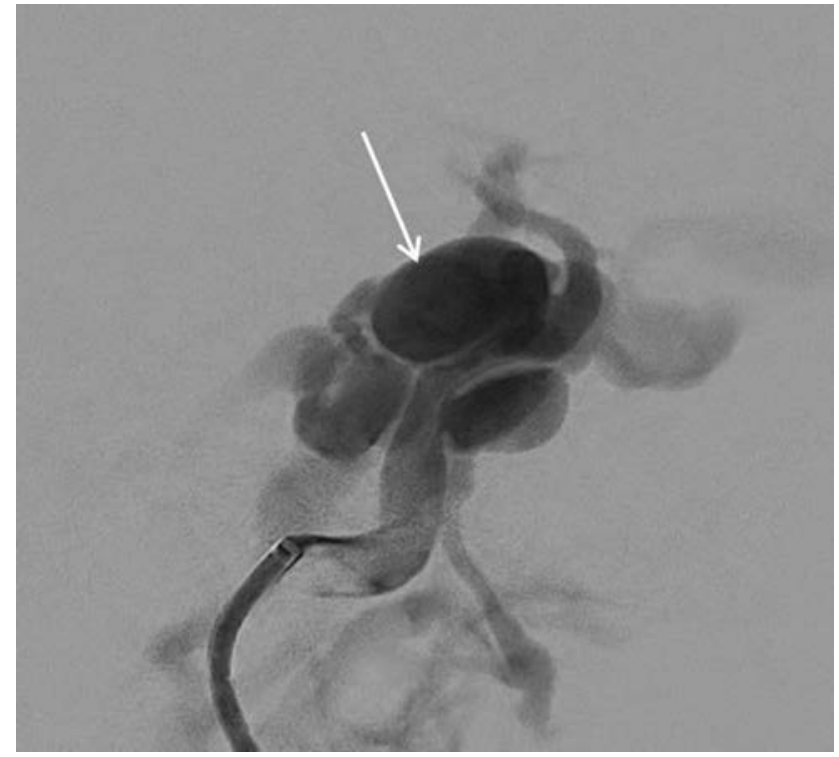

Fig. 8 Lateral angiogram in a case of direct caroticocavernous fistula shows a large varix of cavernous sinus (arrow).

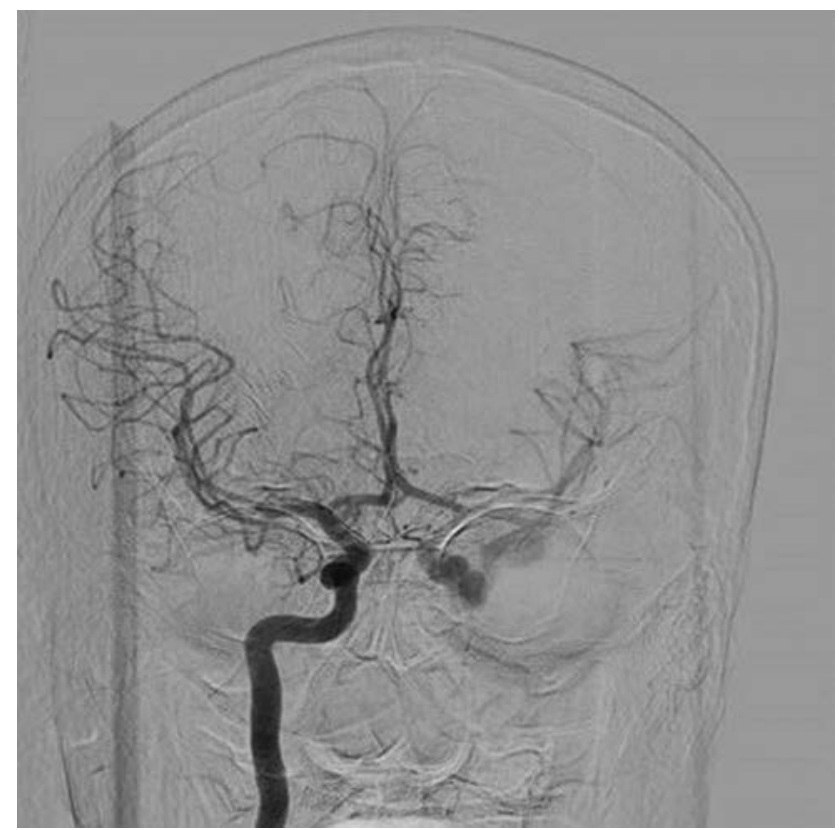

Fig. 9 Right ICA angiogram with manual compression of left CCA in a case of left direct caroticocavernous fistula shows good cross flow across the anterior communicating artery.

In indirect CCFs it is important to note presence or absence of the draining venous sinuses ( - Fig. 11), which would serve as pathways for access to the concerned cavernous sinus.

\section{Treatment Modalities}

For cases with minor symptoms and absence of any dangerous features on angiography, a conservative approach including follow up of intraocular pressures, visual acuity, and cranial neuropathies can be followed. Medical treatment to decrease IOP, corneal protection measures along with manual compression of carotid artery by the patient (while in

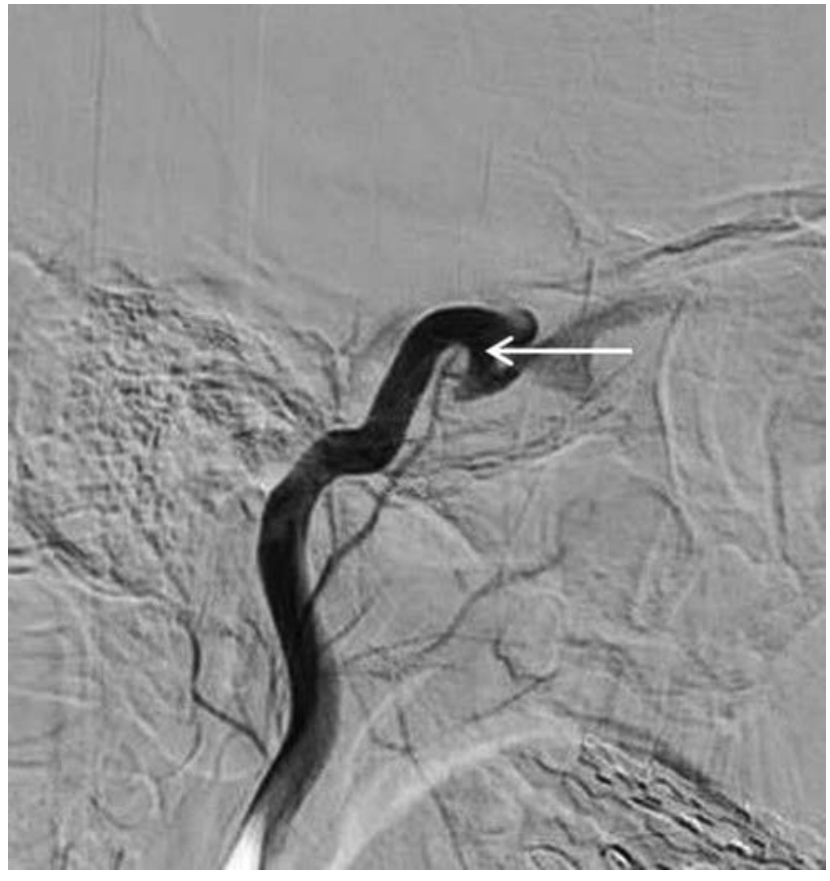

Fig. 10 Left ICA angiogram in a case of direct caroticocavernous fistula ( - Fig. 1) with manual compression of left CCA (Mehringer and Heishiema maneuver) leads to excellent delineation of the rent in cavernous ICA (arrow).

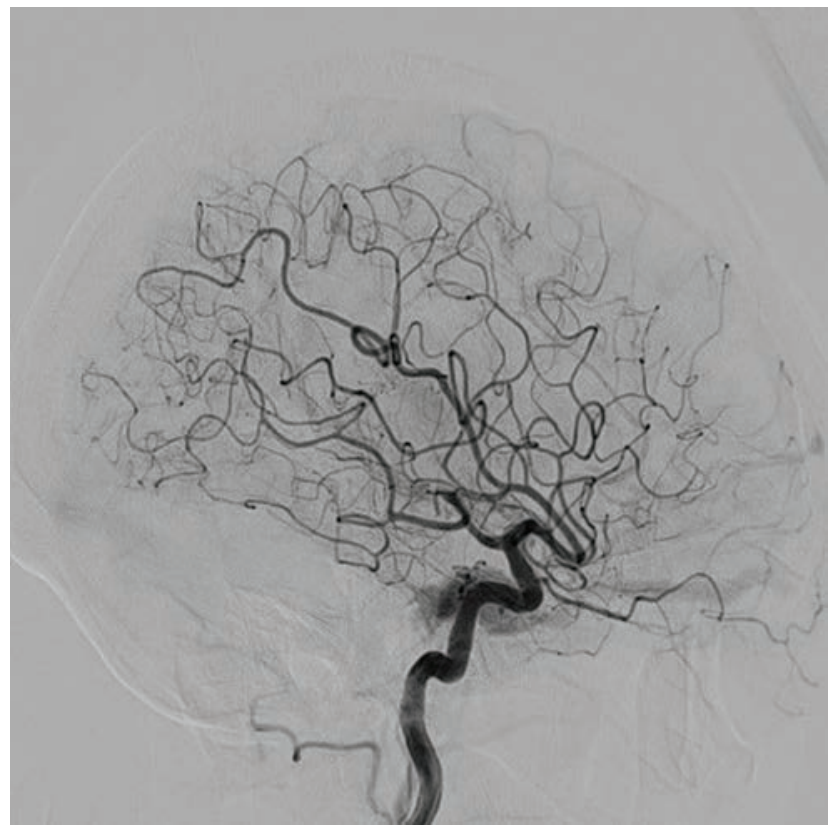

Fig. 11 Late arterial phase of lateral angiogram of right ICA in a case of indirect caroticocavernous fistula shows absence of inferior petrosal sinuses thereby precluding a posterior transvenous approach to enter the cavernous sinus.

a sitting or lying down position using his/her contralateral hand) are part of this treatment plan. ${ }^{2}$

Currently endovascular treatment is the primary mode of treatment for symptomatic CCFs.

Microsurgical treatment of CCFs after frontotemporal cavernous sinus exposure is reserved for symptomatic patients who fail endovascular therapy. ${ }^{1,15}$ 
Stereotactic radiosurgery has been described as a means to treat some indirect CCFs but it has the disadvantage of having a significantly long lag time for its effects to set in and having high recurrence rates. ${ }^{20}$

\section{Endovascular Management for Direct CCF}

The aim is to occlude the tear between the ICA and sinus while protecting the ICA and a transarterial approach is a favored one. Choice of the embolizing material varies from detachable coils, liquid embolizing agents, and detachable balloons.

\section{Coiling of the Cavernous Sinus Using Detachable Coils} This is currently the mainstay of treatment for direct CCF in India since one of the other methods favored earlier, that is, detachable balloons have been of limited availability for the past few years. The approach consists of selectively cannulating the rent in the ICA using a microcatheter and subsequently deploying coils within the cavernous sinus till it is no longer filled (-Figs. 12-14).

In our experience use of a balloon is extremely useful in ensuring dense packing of cavernous sinus while ensuring no coil prolapse into the parent artery. Authors have also described use of liquid embolic agents such as N-butyl cyanoacrylate (n-BCA) and ethylene vinyl alcohol (EVOH) along with coils to cure $\mathrm{CCF}^{2}$

\section{Fistula Occlusion Using Detachable Balloon}

Serbinenko described the first successful case of CCF treated by a detachable balloon (-Fig. 15) while preserving
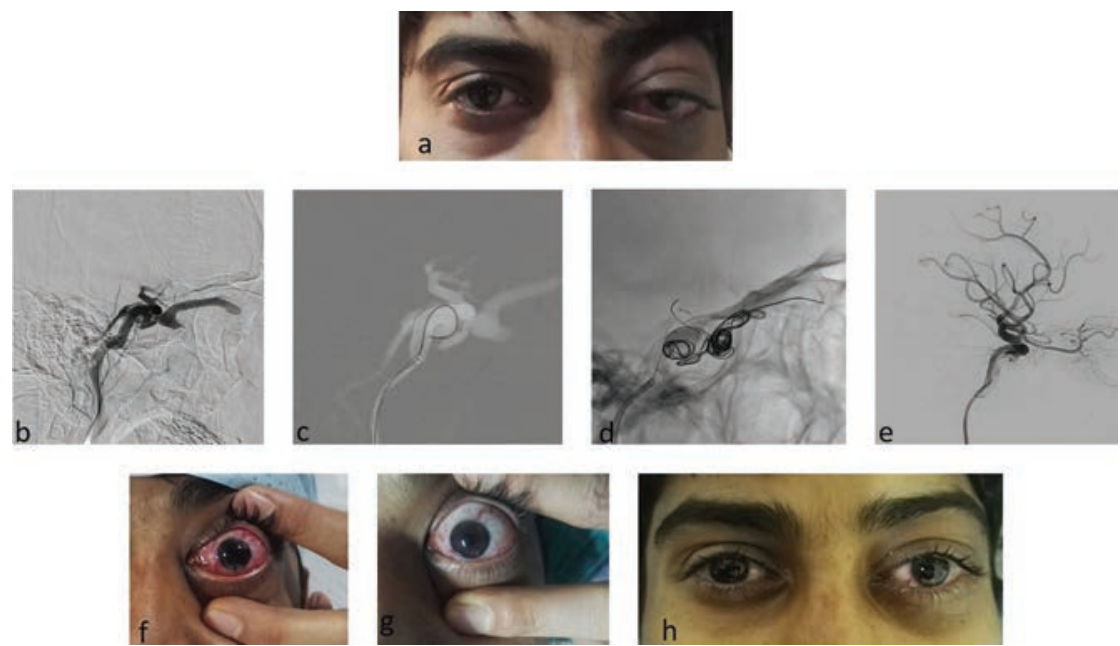

Fig. 12 Balloon-assisted coiling for a case of left direct caroticocavernous fistula. (a) 18-year-old man presented with left proptosis and chemosis 2 weeks post trauma. (b-e) Complete closure of the fistula post coiling. (f,g) Pre- and 3-hour post procedure images showing significant resolution of chemosis. (h) One week post procedure image showing complete resolution of proptosis.
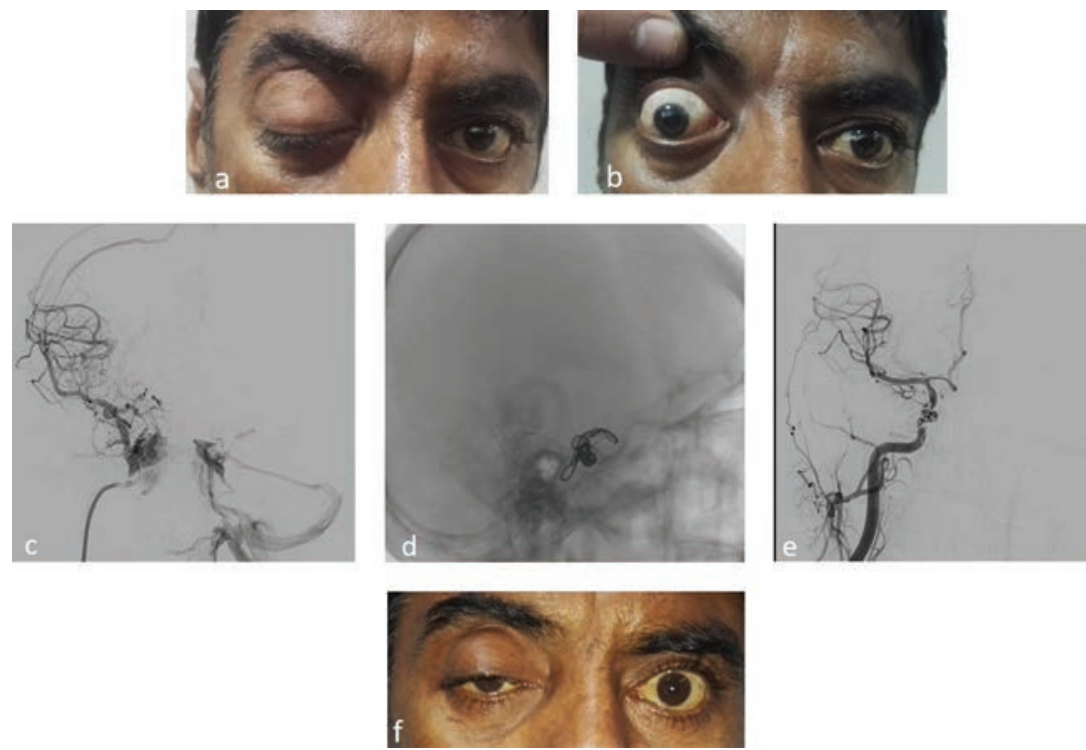

Fig. 13 Balloon-assisted coiling for a case of right direct caroticocavernous fistula. (a,b) A 45-year-old man presented with right proptosis and ptosis ten days post trauma. (c-e) Complete closure of the fistula and deep venous reflux post coiling. (f) One week post procedure image showing partial resolution of proptosis and ptosis but more importantly he is now cured of venous reflux which had a high risk of leading to venous hemorrhage. 

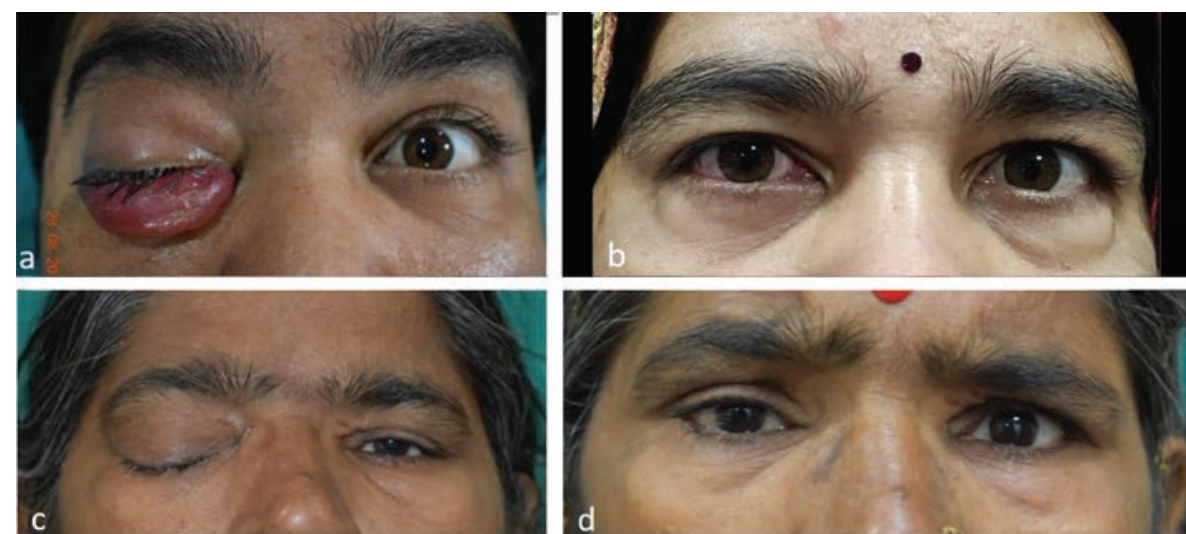

Fig. 14 (a-d) Two patients with right direct caroticocavernous fistulas presenting with extensive chemosis and conjunctival eversion (a) and complete ptosis (b) who were treated with coiling.
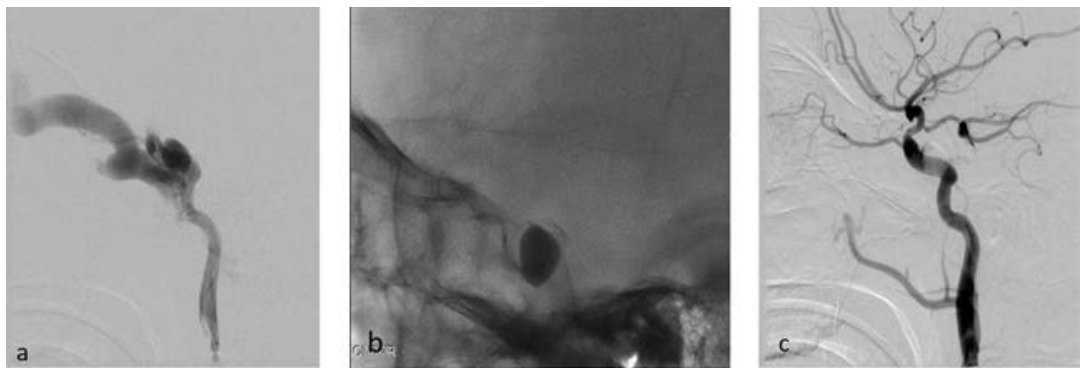

Fig. 15 (a-c) A 17-year-old boy presented with proptosis and chemosis of right eye following road traffic accident. Diagnostic angiogram revealed (a) a direct caroticocavernous fistula with rent located at the horizontal segment of right cavernous ICA. The occlusion of the rent in this case was achieved with a detachable balloon (b). Check angiogram revealed complete occlusion of the fistula and normal filling of the intracranial circulation (c).

the ICA. ${ }^{21}$ The balloon catheter is advanced through a guiding catheter placed high in the cervical ICA and is directed inside the cavernous sinus across the rent due to the flow. Once in place it is inflated and detached. Complications of this procedure include early deflation of the balloon, ${ }^{1,2,15}$ unintended migration of the inflated balloon distal into the ICA, and venous side migration of the balloon. ${ }^{22,23}$

\section{Parent Artery Occlusion (PAO) of ICA}

It may be required in cases when the ICA is extensively damaged and the rent is too big to allow the coils to be accommodated into the cavernous sinus without prolapsing into the ICA. If PAO is planned assessment of collateral flow across the Circle of Willis is essential which may require performing a Balloon test occlusion (BTO) prior to the PAO. It is important to say that if a patient has complete steal through the CCF on DSA and still does not have symptoms of TIA then this would suggest that the collateral flow across the anterior and posterior communicating arteries is adequate and a BTO may not be needed. ${ }^{1.18}$

Methods for PAO include coiling of the ipsilateral ICA (-Fig. 16) in a distal to proximal fashion so as to prevent filling of the fistula in retrograde manner from supraclinoid ICA. ${ }^{1,2,15}$ PAO can also be done by placing two detachable balloons, proximal and distal to the fistula.

\section{Stent Graft Placement in the ICA}

Though navigability of stent grafts into the cavernous ICA is an issue this method has been described by some authors to treat direct CCFs in patients with favorable anatomy. ${ }^{1,15}$ However long-term patency issues preclude their use as a first line method to treat CCFs.

\section{Endovascular Management for Indirect CCF}

Unlike a direct CCF which is approached through a transarterial approach an indirect CCF is best treated by a transvenous approach into the affected cavernous sinus. The aim is to occlude the fistula without disturbing venous drainage in the cortical veins ${ }^{1,2,15}$

Transvenous embolization requires access to the affected cavernous sinus through a preferred posterior approach (through the IJV and subsequently IPS) or if it fails via an anterior approach through the facial vein-SOV pathway. ${ }^{1}$ The latter may require a direct SOV exposure in some cases ( $\boldsymbol{- F i g}$. 17). Much less favored than these two routes are the ones through the cortical veins, lateral pterygoid veins, superior petrosal veins, and inferior ophthalmic veins. ${ }^{1}$ Once the concerned cavernous sinus is accessed embolization is completed using coils and/or liquid agents. ${ }^{1}$ 

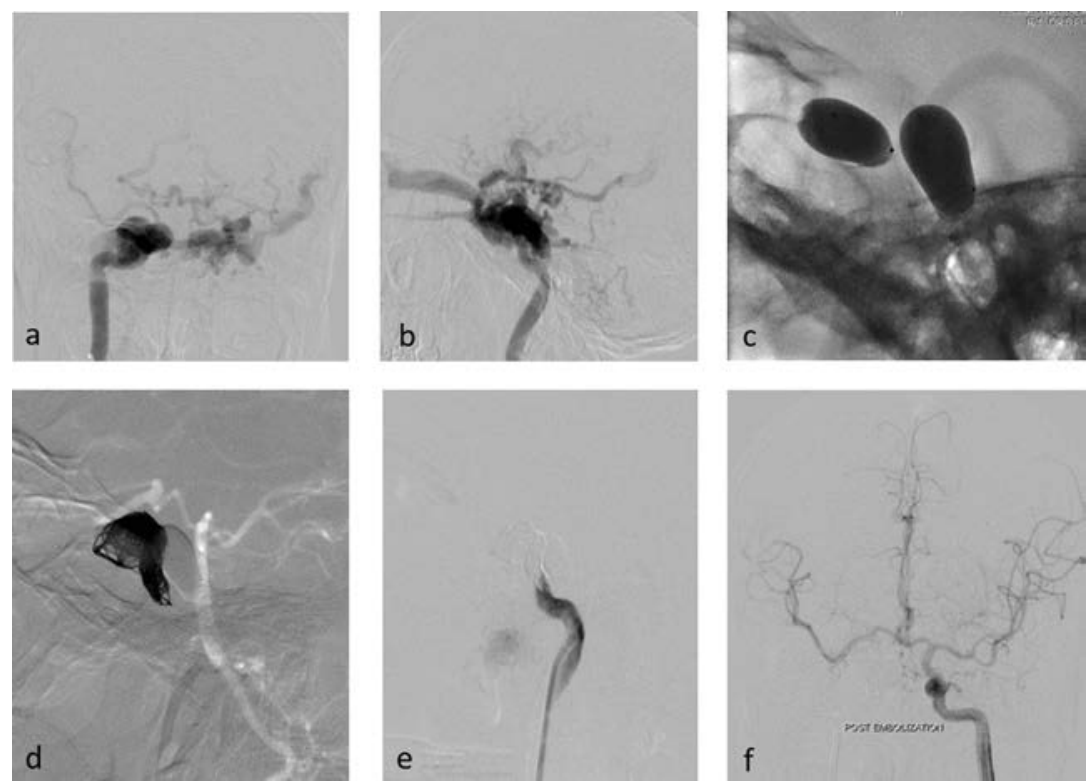

Fig. 16 (a-f) A 26-year-old gentleman presented with right-sided direct caroticocavernous fistula with venous drainage to bilateral superior ophthalmic veins and associated cortical venous reflux $(\mathbf{a}, \mathbf{b})$. The rent was located at the posterior horizontal aspect of cavernous segment of right ICA. Initial attempt to treat the caroticocavernous fistula with detachable balloons (c) was not successful. The case was then managed with parent artery occlusion of right ICA with use of detachable coils (d). Good cross-circulation via the anterior and posterior communicating artery was evident $(\mathbf{e}, \mathbf{f})$ which perfused the right sided anterior circulation. The patient recovered without any deficit.
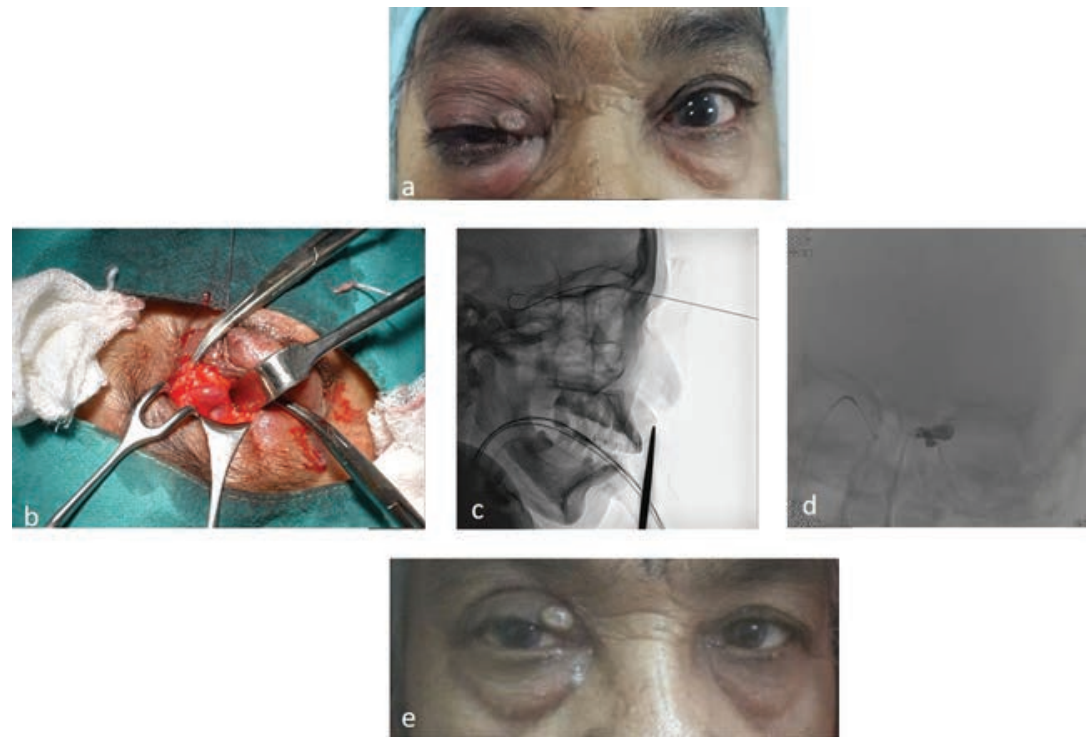

Fig. 17 A case of indirect caroticocavernous fistula (type D2) (a) centered on left cavernous sinus (angiogram shown in $\boldsymbol{-}$ Fig. 2) treated by anterior approach to cavernous sinus by direct exposure of right SOV $(\mathbf{b}, \mathbf{c})$. Post coiling and Onyx embolization of left cavernous sinus (d) the patient showed complete clinical improvement in 4 weeks (e).

\section{Long-term Outcomes}

The long-term follow-up results for endovascular treatment for CCFs are extremely good with a success rate for closure of direct CCFs reported to be from 82 to $99 \%$ and that of indirect CCFs to be from 70 to $78 \%$ without any major procedure related complications. ${ }^{24-26}$

\section{Funding}

None.

\section{Conflicts of Interest}

None.

\section{References}

1 Ringer AJ, Salud L, Tomsick TA. Carotid cavernous fistulas: anatomy, classification, and treatment. Neurosurg Clin N Am 2005;16(2):279-295

2 Tjoumakaris SI, Jabbour PM, Rosenwasser RH. Neuroendovascular management of carotid cavernous fistulae. Neurosurg Clin N Am 2009;20(4):447-452

3 Barrow DL, Spector RH, Braun IF, Landman JA, Tindall SC, Tindall GT. Classification and treatment of spontaneous carotid-cavernous sinus fistulas. J Neurosurg 1985;62(2):248-256

4 Ernst RJ, Tomsick TA. Classification and angiography of carotid cavernous fistulas. In: Tomsick TA, ed. Carotid cavernous sinus fistula. Cincinnati, OH: Digital Education Publishing; 1997:13-22 
5 Connors JJ, Wojak JC. Interventional Neuroradiology: Strategies and Practical Techniques. Philadelphia, PA: WB Saunders Co; 1999:215-226

6 Raskind R, Johnson N, Hance D. Carotid cavernous fistula in pregnancy. Angiology 1977;28(10):671-676

7 Brismar G, Brismar J. Spontaneous carotid-cavernous fistulas: phlebographic appearance and relation to thrombosis. Acta Radiol Diagn (Stockh) 1976;17(2):180-192

8 Toya S, Shiobara R, Izumi J, Shinomiya Y, Shiga H, Kimura C. Spontaneous carotid-cavernous fistula during pregnancy or in the postpartum stage. Report of two cases. J Neurosurg 1981;54(2):252-256

9 Kwan E, Hieshima GB, Higashida RT, Halbach VV, Wolpert SM. Interventional neuroradiology in neuro-ophthalmology. J Clin Neuroophthalmol 1989;9(2):83-97

10 Debrun GM. Treatment of traumatic carotid-cavernous fistula using detachable balloon catheters. AJNR Am J Neuroradiol 1983;4(3):355-356

11 Tomsick TA. Types B, C, and D (dural) CCF: etiology, prevalence, and natural history. In: Carotid Cavernous Fistula. Cincinnati, OH: Digital Educational Publishing; 1997:59-73

12 Yu SC, Cheng HK, Wong GK, Chan CM, Cheung JY, Poon WS. Transvenous embolization of dural carotid-cavernous fistulae with transfacial catheterization through the superior ophthalmic vein. Neurosurgery 2007;60(6):1032-1037

13 Tomsick TA. Type B, C, and D (dural) CCF: etiology, prevalence and natural history. In: Tomsick TA, editor. Carotid Cavernous Sinus Fistula. Cincinnati, OH: Digital Education Publishing; 1997:59-73

14 Halbach VV, Hieshima GB, Higashida RT, Reicher M. Carotid cavernous fistulae: indications for urgent treatment. AJR Am J Roentgenol 1987;149(3):587-593

15 Gemmete JJ, Ansari SA, Gandhi DM. Endovascular techniques for treatment of carotid-cavernous fistula. J Neuroophthalmol 2009;29(1):62-71
16 Meyers PM, Halbach VV, Dowd CF, et al. Dural carotid cavernous fistula: definitive endovascular management and longterm follow-up. Am J Ophthalmol 2002;134(1):85-92

17 McConnell EM. The arterial blood supply of the human hypophysis cerebri. Anat Rec 1953;115(2):175-203

18 Korkmazer B, Kocak B, Tureci E, Islak C, Kocer N, Kizilkilic O. Endovascular treatment of carotid cavernous sinus fistula: a systematic review. World J Radiol 2013;5(4):143-155

19 Rajagopal R, Mehta N, Saran S, Khera PS. Heuber maneuver in evaluation of direct carotid-cavernous fistula. Pol J Radiol 2016;81:483-485

20 Pollock BE, Nichols DA, Garrity JA, Gorman DA, Stafford SL. Stereotactic radiosurgery and particulate embolization for cavernous sinus dural arteriovenous fistulae. Neurosurgery 1999;45(3):459-466

21 Serbinenko FA. Balloon catheterization and occlusion of major cerebral vessels. J Neurosurg 1974;41(2):125-145

22 Sencer S, Minareci O, Poyanli A. Management of a rare complication of endovascular treatment of direct carotid cavernous fistula. AJNR Am J Neuroradiol 1999;20(8):1465-1466

23 Klisch J, Schipper J, Husstedt H, Laszig R, Schumacher M. Transsphenoidal computer-navigation-assisted deflation of a balloon after endovascular occlusion of a direct carotid cavernous sinus fistula. AJNR Am J Neuroradiol 2001;22(3):537-540

24 Halbach VV, Higashida RT, Hieshima GB, Reicher M, Norman D, Newton TH. Dural fistulas involving the cavernous sinus: results of treatment in 30 patients. Radiology 1987;163(2):437-442

25 Higashida RT, Halbach VV, Tsai FY, et al. Interventional neurovascular treatment of traumatic carotid and vertebral artery lesions: results in 234 cases. AJR Am J Roentgenol 1989;153(3):577-582

26 Gupta AK, Purkayastha S, Krishnamoorthy T, et al. Endovascular treatment of direct carotid cavernous fistulae: a pictorial review. Neuroradiology 2006;48(11):831-839 